\title{
What Technology-enabled Services Do Air Travelers Value? Investigating the Role of Technology Readiness
}

\begin{abstract}
An increasing use of technology in service delivery presents challenges for businesses, in particular in relation to how customers perceive specific technology-enabled services (TESs) and which TESs they embrace. This study investigates the influence of technology readiness (TR) on travelers’ perceived importance of various airline TESs. Results reveal three categories of TESs: Established, Network Access and New. Two dimensions of TR-Optimism and Innovativeness—-were significantly associated with the perceived importance of TESs.

Respondents who reported higher levels of Optimism rated Established TESs as particularly important. In contrast, respondents high on Innovativeness rated Network Access and New TESs as more important. The association between TR dimensions and perceived importance of TESs was more evident in customers of low-cost carriers than in customers of full-service airlines. This study contributes to the TES and TR literature by explaining why a TES may be more (or less) important to different customers through the association of the TR construct.
\end{abstract}

Key words: technology-enabled services, technology readiness, airline 


\section{INTRODUCTION}

Airlines are adopting a range of increasingly sophisticated technology-enabled services (TESs), including self-check-in facilities in airports, mobile technologies such as mobile boarding passes and reservation systems, and Internet access on board. Consequently, travelers have to deal with services that are becoming more technologically sophisticated (J. S. C. Lin \& Hsieh, 2007). When encountering technologies, customers may vary in their psychological reactions, depending on the individual's feeling about technologies (J. S. C. Lin \& Hsieh, 2007). One important factor influencing consumers' reaction to technology is technology readiness (TR), which measures customers’ mental readiness to embrace technologies (Parasuraman, 2000).

This study seeks to explain the role of customer TR in travel-related service consumption. In particular, the study examines the influence of TR dimensions on customers’ perceived importance of airline TES features and explores whether TR's influence varies across different types of TESs and airlines. The airline industry was selected as the empirical setting because (1) air travel is an integral component of most tourist experiences, (2) the airline industry accounts for a significant share of the tourism industry’s economic output and investment (Tourism Research Australia, 2012a, 2012b), and (3) airlines have been at the forefront of the general trend of moving toward more strategic use of technologies (International Air Transport Association, 2011).

The wide range of TESs in use by airlines offers an excellent opportunity to understand TES-related phenomena. By investigating how TR may affect the importance customers place on airline TES attributes, this study addresses the literature gap in relation to:

- Use of TESs, particularly in a tourism service context: Empirical research on TESs is limited (Beatson, Coote, \& Rudd, 2006; Gelderman, Ghijsen, \& van Diemen, 2011; J. S. 
C. Lin \& Hsieh, 2007; Meuter, Ostrom, Roundtree, \& Bitner, 2000), especially in a tourism and hospitality context. Importantly, TESs often seem mis-matched to customer needs (Matthing, Kristensson, Gustafsson, \& Parasuraman, 2006), creating a need for research into the use of TESs in service delivery.

- Factors influencing TES-related attitudes and behaviors: Studies investigating customer attitudes and behavior toward TESs have primarily taken the firm's perspective (e.g., Cheng \& Cho, 2011; Kokkinou \& Cranage, 2012), with the result that knowledge regarding factors influencing customers' use and evaluation of technology-based services is very limited (J. S. C. Lin \& Hsieh, 2007). When such studies were undertaken, investigators often gave attention primarily to determinants such as perceived usefulness, ease of use, and compatibility, which are characteristics of technologies (e.g., M. Kim \& Qu, 2014). In addition, research exploring individual differences in the use and evaluation of information technologies has tended to focus on social demographic characteristics such as gender, age, and income. However, researchers are progressively recognizing the importance of understanding consumers' technology beliefs and readiness to engage with information systems (Massey, Khatri, \& Montoya-Weiss, 2007).

- The role of TR in technology-enabled service consumption: Compared to other personal traits, TR is a relatively new construct supported by little empirical research into its role in service consumption (Liljander, Gillberg, Gummerus, \& van Riel, 2006; J. S. C. Lin \& Hsieh, 2007), even at a time when major technology advancements are being applied to the delivery of tourism services. In addition, research often treats TR as an overall measure without differentiating its dimensions (e.g., C. H. Lin, Shih, \& Sher, 2007; J. S. C. Lin \& Hsieh, 2007; Westjohn, Arnold, Magnusson, Zdravkovic, \& Zhou, 2009), and 
tends to focus on a single TES or a small number of TESs rather than attempting to examine the range of TESs available to customers (Meuter et al., 2000).

In short, TR's association with customers' attitudes and experience in relation to TESs remains largely unexplored. From data collected through an online survey, this study found that customers differentiated established airline TESs from those that are relatively new, and that TR dimensions were associated with different types of TESs. By conceptualizing and testing the relationships between TR dimensions and types of TESs, this study offers practical insights into why some customers place greater importance on certain TESs than on others. This understanding supports airlines' efforts to create an appropriate TES portfolio, educate customers, and market TESs to the right customer groups.

\section{LITERATURE REVIEW}

\section{Airline TESs}

Airlines are under increasing pressure from customers to invest further in guest-focused technology (Hoon, 2012). Furthermore, technological innovations play a critical role in the development of the modern airline industry, helping airlines reduce costs, increase speed and capacity, mitigate environmental impact, manage security, and introduce flexibility into products (International Air Transport Association, 2011; D. Y. Kim, Park, \& Morrison, 2008). These innovations not only strongly affect the production of airline service but also assist in the marketing of airline services (D. Y. Kim et al., 2008). In addition, TES innovations can provide opportunities for differentiation and potential revenue streams (D. Y. Kim et al., 2008). For the purpose of this study, TESs are defined as services delivered through modern technologies. Unlike self-service technology, which permits customers to produce service without a service 
employee’ assistance (Kokkinou \& Cranage, 2012), a TES may be operated by either customers or airline employees.

Airline TESs are likely to offer customers many possible benefits, from those that are highly functional (e.g., saving time and costs) to those that are highly hedonic or fun (Massey et al., 2007). Different TESs may also be at different phases of their technology lifecycle, from introduction to growth, maturity, and decline (Rogers, 1995). For example, some airline TESs, such as email contact and direct booking on airline or third-party websites, are widely used by travelers for cost and time savings, convenience, and other benefits. These TESs have become relatively mature and well established across most airlines. In contrast, TESs such as a presence on social media, Wireless Application Protocol (WAP)-based reservation systems, and smart phone check-in are newly introduced and may provide travelers with an additional sense of excitement and novelty.

\section{Technology Readiness}

Customers' perception and use of TESs are influenced by their TR, which is their “propensity to embrace and use new technologies” (Parasuraman, 2000, p. 308). TR comprises four dimensions:

- Optimism: a positive belief in technology's ability to offer people increased control, flexibility, and efficiency in their lives;

- Innovativeness: a tendency to be a technology pioneer and thought leader;

- Discomfort: a perceived lack of control over technologies; and

- Insecurity: a feeling of distrust or skepticism toward technology and its ability to function properly. 
The four dimensions are conceptually distinctive, with Optimism and Innovativeness being mental enablers of technology use and Discomfort and Insecurity representing inhibitors. These paradoxical dimensions have been described as coexisting in individuals to shape their behavior toward technologies (Massey et al., 2007; Parasuraman, 2000). Compared to other measures, such as personal innovativeness and technology anxiety, TR has the advantage of comprehensiveness. With its four distinctive dimensions, TR is a more integrative measure of people’s propensity to embrace technology (Yi, Tung, \& Wu, 2003). TR is also conceptualized as a personal trait. Therefore, the TR dimensions are relatively stable descriptors of individuals and are invariant across circumstance (Walczuch, Lemmink, \& Streukens, 2007). TR is operationalized by the Technology Readiness Index, which exists in three versions (36-item, 10item, and 6-item), all copyrighted by Parasuraman and Rockbridge Associates, Inc.

As TR can positively affect customers' attitude and behavior toward a technologyenabled service (C. H. Lin et al., 2007), a reasonable assumption is that when evaluating a product, customers high in TR would regard the product's technological features as being more important than would customers low in TR. However, two studies of airlines reveal that TR has little impact on customers' attitudes and adoption of TESs. A study of self-check-in kiosks failed to show a positive impact of TR on the actual use of this service (Gelderman et al., 2011). Another study found that although overall TR shows a relatively consistent association with willingness to use, service quality perception, satisfaction, and loyalty to self-service options, an investigation into the effect of individual TR dimensions generated mixed results (Liljander et al., 2006).

While Optimism has a moderate effect on willingness to use TESs, Innovativeness is only weakly associated with the willingness to use mobile and Internet services, and does not affect 
the use of kiosks and personal services. In addition, Innovativeness does not affect service quality perception, satisfaction, or loyalty. In other words, overall TR and its Optimism dimension are better predictors than Innovativeness. However, these studies employed only one self-check-in kiosk and three TESs (self-check-in using mobile service, Internet, and kiosk), respectively. Whether the TR dimensions would have similar effects on other TESs is not clear, and the relationship between TR dimensions and different types of TESs has not been empirically tested.

\section{Research Hypotheses}

TESs provide functional benefits to customers such as convenience, efficiency, and productivity, which are linked to extrinsic motivations to achieve specific goals (Venkatesh \& Brown, 2001). For instance, websites (both the airlines’ own and third-party booking sites) have become the dominant channels through which travelers book flights (International Air Transport Association, 2011), and a self-check-in kiosk can reduce waiting time during high demand periods (Kokkinou \& Cranage, 2012). As mentioned, TR’s Optimism dimension refers to a belief in technology’s ability to offer increased control, flexibility, and efficiency (Parasuraman, 2000). As optimism is a mental enabler that positively affects perceived usefulness of a technology (Walczuch et al., 2007), customers holding a more optimistic view of technology are likely to perceive airline TESs to be more instrumental in achieving a convenient and efficient booking and flight experience, and would value these TESs more highly when making a purchase decision. While prior research has highlighted perceived usefulness as an antecedent of customers' intention to use a TES, this study focuses on perceived importance of TES, which also has a strong influence on consumers’ purchase decision making and consumption experiences (e.g., Pentecost \& Andrews, 2013; Tam, 2011). 
Two factors influenced the selection of perceived importance in the context of this study. First, perceived usefulness reflects primarily the instrumental value, or utility, of a TES, whereas perceived importance can more comprehensively capture the value that a customer places on a product, which may be driven by both instrumental benefits and enduring beliefs (Tam, 2011). Second, the product of concern to customers in this study is a flight experience, where TESs are its attributes. Our interest is in TR's influence on purchase decision making rather than its impact on customers' intention to use TES features during the flight. While a traveler may perceive a TES to be useful, he or she may not necessarily intend to use the TES feature. Customers are also not likely to want to use all TESs made available by an airline. The above discussion leads to the following hypothesis:

Hypothesis 1: Optimism has a positive association with the perceived importance of TESs.

As Innovativeness is a tendency to be a technology pioneer and thought leader (Parasuraman, 2000), customers who are high on Innovativeness are more likely to develop positive perceptions about technological innovations (Agarwal \& Prasad, 1998; Rogers, 1995) and to have stronger intrinsic motivations to seek new innovations. Innovative customers are also better at dealing with technology-related uncertainties (Agarwal \& Prasad, 1998). In the process of satisfying their intrinsic needs, customers experience hedonic benefits, such as feelings of self-fulfilment and development (van der Heijden, 2004), and to satisfy these motivations, innovative customers are willing to try new technologies despite the possible difficulties of using them and the greater risks and uncertainties associated with them (Yi et al., 2003).

However, not all technologies appeal to innovative customers. For example, research has found that innovativeness is positively related to attitude toward high-technology-contact 
services but negatively associated with low-technology-contact services, indicating a reversible effect of innovativeness dependent on the characteristics of the technologies (Theotokis, Vlachos, \& Pramatari, 2008). One such characteristic is the newness of a technology. Newness can be categorized as either radical or incremental, presenting different levels of risk, comfort, and familiarity and appealing to different groups of customers (Karande, Merchant, \& Sivakumar, 2011). Roger’s (1995) technology adoption model places innovators at the introduction phase of a technology's lifecycle, suggesting that innovative customers may be attracted only to technologies newly released to the market.

In line with these characterizations, empirical research shows that innovativeness is negatively associated with perceived usefulness of a technology (Walczuch et al., 2007). Similarly, investigators have found a negative relationship between innovativeness and on-line banking adoption (Liljander et al. 2006). These two studies tentatively attributed the negative effect of innovativeness to the uniqueness of the particular technology under study and the possibility that innovative customers are more aware of the latest trends in technology and do not consider on-line banking to be an exciting innovation. These findings suggest that a reasonable assumption is that only newly introduced TESs can satisfy innovators' novelty-seeking motivation. As established TESs, used by the majority of customers, do not provide a sense of innovation, innovative customers may discount the value of these services. On this basis, we propose the following hypotheses:

Hypothesis 2: Innovativeness has a negative association with the perceived importance of established TESs (e.g., airline websites and express check-in kiosks that airlines have adopted across the board). 
Hypothesis 3: Innovativeness has a positive association with the perceived importance of new TESs (e.g., mobile-based reservation systems and presence on social media).

Discomfort refers to a perceived lack of control over technologies (Parasuraman, 2000), and the level of control customers feel in service interaction affects the perceived value of a service (Zhu, Wymer, \& Chen, 2002). Customers who feel highly uncomfortable with technologies perceive technologies to be complex and difficult to use, resulting in a belief that technology detracts from the service experience rather than facilitating the experience. In contrast, customers who feel more comfortable with technology and in control of the process of using technology-enabled services are likely to value TESs more (Zhu et al., 2002) and have a stronger intention to use these services (Dabholkar, 1996).

Insecurity is a feeling of distrust or skepticism toward technology and its ability to function properly (Parasuraman, 2000). Studies of information systems have described trust as a key predictor of technology use and customer perception of technologies (Li, Hess, \& Valacich, 2008), and trust helps users to overcome perceived risk and uncertainty in using technologies. In contrast, lack of trust reduces the expectation of benefits from technology innovation and results in higher resistance to technological innovation (Liljander et al., 2006; Oh, Jeong, Lee, \& Warnick, 2013). The TR definition of insecurity is similar to that of performance-based risks (Featherman \& Pavlou, 2003), which include the possibility of a product malfunctioning and not performing to deliver the expected outcome. As suggested, performance-based risk perceptions can adversely affect the perception and adoption of e-service.

A study of airline passengers reveals that passengers often choose conventional check-in service because of discomfort and insecurity associated with using TESs such as kiosk and web check-in services (Lu, Choi, \& Tseng, 2011). Even if customers are able to see the benefits of 
using self-service technologies, they may still avoid these technologies because of discomfort (Meuter, Ostrom, Bitner, \& Roundtree, 2003). The above discussion leads to the following hypotheses:

Hypothesis 4: Discomfort has a negative association with the perceived importance of TESs.

Hypothesis 5: Insecurity has a negative association with the perceived importance of TESs.

Situational factors strongly affect the use of self-service (Dabholkar, 1996; Oh et al., 2013) and may moderate the influence of a personal trait (Weiten, 2004). One airline-related situational factor is type of airline. According to the International Air Transport Association (2011), full-service airlines and low-cost carriers (LCCs) are the two main segments of the airline industry. The LCC business model is based on innovation (Shaw, Bailey, \& Williams, 2011), which is reflected in the LCCs' more sophisticated use of technologies to improve productivity and product offerings. LCCs have led technology adoption in the areas of edistribution and dynamic pricing, direct website sales, social media engagement, and ancillaries (Hoon, 2012; Torres, Barry, \& Hogan, 2009). For instance, Air Asia, which is an LCC, was the world's first airline to offer SMS booking, and its distribution of LCC flights is predominantly online and through direct booking (O’Connell \& Williams, 2005). As LCC customers have become accustomed to the high-tech and low human touch environment of these airlines, they are more likely to rate TESs as more important.

Customers of full-service airlines often have the option to choose between a technologyenabled and an interpersonal encounter, and human-based technical support is often available to customers using a TES. In addition, full-service airlines continue to use travel agents. Because 
in-person service is available, customers may not feel the need to use an airline's technologyenabled alternative (Meuter et al., 2003). LCCs, on the other hand, have been criticized for lack of customer services (O’Connell \& Williams, 2005; Torres et al., 2009). Customers are expected to use self-service options with limited support from service staff. Some customers believe that LCCs deliberately make contact details difficult to find in order to minimize the need to provide assistance, particularly in relation to handling complaints (Torres et al., 2009).

In short, LCCs present a more sophisticated and challenging environment for TES use. As highly technology-ready customers have a greater intention to embrace technologies and are better able to handle TESs, they may demand more sophisticated provision of TESs and consider TESs to be more important in the LCC environment. This study thus proposes that

Hypothesis 6: The type of airline (i.e., full-service vs. LCC) moderates the effects of TR dimensions on TESs.

\section{RESEARCH METHODS}

The proposed research hypotheses were tested by a quantitative method that included the development of a structured online survey.

\section{Survey Instrument and Measures}

To gather data, the research team used a questionnaire that included measures of customer TR and perceived importance of airlines’ TESs, as well as questions about respondents' social demographics (e.g., age, gender, and educational background) and travel behavior (e.g., tendency to fly with full-service/LCCs, travel purpose, and frequency).

$T R$ scale. With permission for academic use from the copyright owners (i.e., Parasuraman \& Rockbridge Associates, Inc.), the study used the 10-item abbreviated Technology Readiness Index to measure customer TR. This scale has been adopted by previous researchers (Lee, Chiu, 
Chiang, \& Chiu, 2009; C. H. Lin, 2009). Respondents were informed that the purpose of the scale is to obtain their opinions of new technologies. For each of the 10 items, respondents indicated the extent to which they agreed or disagreed on a 7-point Likert-type scale $(1=$ strongly disagree and 7 = strongly agree). An example item is “Technology makes me more efficient in my occupation.” The questionnaire is available on request from the first author.

Airline TES scale. An airline TES scale comprising 33 TES items was developed in a two-step approach. The research team first compiled the TES list from desktop research into academic literature, industry reports, and travel websites and blogs. The team then invited top managers in the airline industry to comment on whether their airlines had implemented the listed TESs, and if not, whether the airlines planned to implement these TESs in the near future. Responses from top managers of four major airlines (two full-service airlines and two LCCs) in Oceania helped to refine the scale. Respondents were asked to rate the importance to them of each of the TESs when booking a flight, using a 7-point Likert-type scale $(1=$ not at all important and 7 = very important) with the leading question being "How important do you think each of these TESs is to your selection of a flight/an airline when making a booking?” All TESs and TR items were randomized to exclude any systematic influence of the order of items on responses. Respondents were asked to tick the option of "Never heard of it” if they had no knowledge about a TES.

Pre-test and pilot test. The questionnaire was set up on Qualtrics, a reputable website for research surveys. To identify potential issues related to survey flow, readability, and logistics, a convenience sample of 73 faculty members and higher degree research students in a large Australian university participated in the pre-test phase, resulting in minor changes to the wording of several questions to better suit the study context. A pilot test involving 161 participants then 
followed, with assistance from a reputable marketing list company for a validity check and a further logistics test. The pilot test identified no major issues.

\section{Survey Procedure and Participants}

The marketing list company used in the pilot test also provided access to the sample in the main data collection phase. On behalf of the research team, the company sent an invitational email with an embedded survey link to selected members of its research panel. The email provided details on the research project and its ethical clearance and invited panelists to anonymously and voluntarily participate in the study. Using a quota sampling approach, the marketing list company delivered a final sample that met several criteria, including (1) over 18 years of age, (2) gender balance, (3) distribution across age groups, and (4) geographic spread across Australian states and territories. The survey started with a screening question to exclude customers who had not had a recent flight experience. A total of 485 usable responses were obtained for analysis.

\section{RESULTS}

Table 1 summarizes the demographic characteristics of the sample. Respondents were evenly distributed across gender and age groups, and the majority had an undergraduate education and were married or in a de facto relationship at the time of data collection. In addition, about $59.7 \%$ indicated a tendency to fly with full-service airlines compared to $40.3 \%$ for budget airlines.

\section{Insert Table 1 here}

Following the approach suggested by Armstrong and Overton (1977), the research team assessed non-response bias by comparing early and late respondents on the demographic variables and the scale measures. The chi-square tests indicate no significant differences between 
early (top 10\%) and late (bottom 10\%) respondents in terms of respondent characteristics. In addition, the $t$-test results show that all measured items were not significantly different ( $\alpha=.01)$ between early and late respondents. These analyses indicate no serious non-response bias.

\section{Data Preparation}

As the TR measurement items are well established in the literature, an exploratory factor analysis (EFA) was conducted only on the TES items to explore the underlying factor structure of the data, because they were newly devised for this study. To ensure the adequacy of the sample size and the appropriateness of the EFA, both the Kaiser-Meyer-Olkin (KMO) measure of sampling adequacy and Bartlett's test of sphericity were performed. The KMO value of .96 exceeded the recommended level of .60 (Tabachnick \& Fidell, 2001), and the result of the Bartlett's test of sphericity was 9411.06, $d f=595(p<.001)$, suggesting that the factor analysis was appropriate. An EFA performed on the data resulted in deletion of 12 items owing to crossloadings or factor loadings of below .40. Subsequently, as the resultant factors were assumed to be correlated, a factor analysis was conducted on the remaining 21 items using the maximum likelihood estimation method with oblique rotation. Use of eigenvalues of greater than 1.0 and Cattell's (1966) scree test as guidelines for factor extraction revealed three groups of the TESs, which were labeled "Network Access," "Established," and "New” TESs (abbreviated as NET, EST, and NEW in result reporting). Altogether, the three-factor model explained $79.17 \%$ of the total variances. As Table 2 shows, all three factors exceeded the Cronbach's alpha criterion of .70 (Hair, Black, Babin, Anderson, \& Tatham, 2006), with no cross-loadings in excess of .40.

For a number of years, airlines have widely employed Established TESs, such as web check-in, express check-in kiosks, online booking, and presence on major booking websites, which travelers use for core functionalities such as reservation, check-in, and in-flight 
entertainment. In contrast, Network Access and New TESs are relatively recent service offerings. Network Access includes TESs related to Internet and Intranet access on board and in the airport. Although the Internet has fundamentally changed the way people live and work, in-flight network access has not been widely introduced to Australian travelers. New TESs are largely peripheral rather than core functional attributes of the booking and flight experience.

Insert Table 2 here

\section{Hypothesis Testing}

To test Hypotheses 1 to 6, the research team adopted a structural equation modeling (SEM) approach. This section first evaluates the measurement model and then examines proposed research hypotheses through assessment of the structural model.

Measurement model. A confirmatory factory analysis (CFA) was conducted using the three TES factors identified through EFA together with four TR factors taken from an established scale: Optimism (OPT), Innovativeness (INN), Discomfort (DIS), and Insecurity (INS). The measurement model resulted in a significant chi-square value of 1218.73 ( $d f=418, p$ $<.001$ ), which is highly sensitive to sample size. However, the ratio of the chi-square to degrees of freedom $\left(\chi^{2} / d f=2.95\right)$ is below the recommended cut-off point of 3 (Bagozzi \& Yi, 1988). Overall, the measurement model achieved acceptable fit $(\mathrm{CFI}=.90, \mathrm{NFI}=.87, \mathrm{TLI}=.88$, and RMSEA $=.063)$, as shown in Table 3.

Insert Table 3 here

In addition, the validity and reliability of each scale were examined. Convergent validity was evidenced with statistically significant $(p<.01)$ item factor loadings (Anderson \& Gerbing, 1988). As indicated in Table 3, standardized factor loadings for all items ranged from moderate to strong, with $t$-values greater than 2.57 (Netemeyer, Bearden, \& Sharma, 2003), suggesting that 
all items are significant indicators of their respective constructs $(p<.01)$ and providing support for convergent validity.

To establish discriminant validity of the measured constructs, the method suggested by Bagozzi and Heatherton (1994) and Anderson and Gerbing (1988) was used to test whether the correlation between constructs is significantly less than one. This test involves the computation of the confidence interval for each correlation estimate. Discriminant validity is evidenced if the value of one is not within two standard errors of the correlation. The results of this analysis show the highest correlation between constructs was .83 (between DIS and INS). The associated confidence intervals were .58 to .89 , respectively. Therefore, discriminant validity was supported for all pairs of constructs.

Construct reliability was evaluated through composite reliability. The formula of Fornell and Larcker (1981) was used to calculate composite reliability measures and with one exception (DIS), all factors achieved the recommended level of construct reliability ( $\alpha>$.70) (Hair et al., 2006). The failure of DIS to achieve reliability may be due to the instability of the negative dimensions of the TR scale, which has been reported in previous studies (e.g., Gelderman et al., 2011; Liljander et al., 2006). Overall, the preceding statistical tests provide strong empirical support that the scales were valid and reliable measures of their respective constructs.

Structural model. The overall structural model was tested using AMOS 18.0 with maximum likelihood estimation. The results presented in Table 3 indicate a good model fit $\left(\chi^{2}=\right.$ 1218.73, $d f=413, p<0.001, \chi^{2} / d f=2.95, \mathrm{CFI}=.90, \mathrm{NFI}=.86, \mathrm{TLI}=.88$, and $\left.\mathrm{RMSEA}=.063\right)$. The structural path coefficients suggest that of the twelve paths, five were significant (i.e., $\mathrm{OPT} \rightarrow \mathrm{ESD}, \mathrm{INN} \rightarrow \mathrm{ESD}, \mathrm{INN} \rightarrow \mathrm{NET}, \mathrm{OPT} \rightarrow \mathrm{NET}, \mathrm{INN} \rightarrow \mathrm{NEW})$. Discomfort and Insecurity 
were not significant for any pathways. Results of hypotheses testing are presented in Table 4 with beta weights of the hypothesized paths and model fit statistics.

\section{Insert Table 4 here}

As the analysis in Table 4 shows that in the overall structural model, all paths from INS and DIS are not significant in predicting perceived importance of the three TES factors, the model was re-estimated without these two negatively valanced dimensions (see Figure 1). The results are generally consistent with those of the full model with the exception of one path (i.e., $\mathrm{OPT} \rightarrow \mathrm{NET}$ ) that has changed from being significant at the $5 \%$ level to $10 \%$ (see Table 5). These results support Hypotheses and 3 and partially support Hypothesis1, but do not support Hypotheses 4 and 5.

Insert Figure 1 here

Insert Table 5 here

\section{Testing for the Moderating Effects of Type of Airline}

To test the moderating effects of type of airline (i.e., full-service vs. low-cost), the sample was divided into two groups on the basis of the type of airline that the respondents tended to fly with. Individual SEMs were subsequently conducted on Model A (full service, $n=285$ ) and Model B (low cost, $n=192$ ), and the results of the hypothesized paths are presented in Table 6 . The analysis revealed differences in path significance. With $5 \%$ as the level of significance, two paths, OPT $\rightarrow$ ESD and INN $\rightarrow$ NEW, are significant in both groups, but the path from INN to NET is supported only in the full-service model and that from OPT to NET is supported only for the low-cost group. With a level of $10 \%$ as the cut-off, all paths except OPT $\rightarrow$ NEW are significant for the low-cost group. In contrast, three paths are not significant in the full-service 
model. Thus some support exists for moderation by type of airline for the effect of TR dimensions.

To formally compare the strengths of the paths, a multi-group analysis was conducted to first assess measurement invariance, which is considered to be a requirement for meaningful group comparison. The results of the chi-square difference test indicate that the full metric

invariance model was not significantly worse than the unconstrained model $\left(\Delta \chi^{2}(30)=38.58, p\right.$ $>$.05), supporting factor invariance across groups. Therefore, a parameter comparison was conducted. The resulting z scores for parameter differences indicated that, of the six paths, only one (i.e., OPT $\rightarrow$ NET) was significantly different between groups at the $10 \%$ level $(\alpha=.10)$. Therefore, Hypothesis 6 is only partially supported at the $90 \%$ level of confidence.

Insert Table 6 here

\section{DISCUSSION AND IMPLICATIONS}

The primary objective of this study was to examine the relationship between TR and the importance of airline TES features to customers when booking a flight. The findings suggest that customers categorize airline TESs into three categories-Established, Network Access, and New TESs_-based on perceived importance of these TESs. This categorization provides a simple customer-based typology for airline TESs in which customers seem to differentiate TESs largely on the basis of how well established the TESs are in the air service context.

The study tested a number of hypotheses related to the influence of individual TR dimensions on the perceived importance of the three groups of TESs. Optimism is positively associated with Established TESs, but not Network Access and New TESs, partially supporting Hypothesis 1. As the results show, Established TESs include widely implemented services such as web check-in, express check-in kiosks, online booking, and presence on major booking 
websites. These TESs are alternatives to traditional in-person booking and check-in services, providing the convenience of booking flights at home and offering time-saving measures such as avoiding queues in the airport. Customers are likely to be familiar with the established TESs and can comfortably operate these TESs (J. S. Kim, Christodoulidou, \& Brewer, 2012). Owing to a higher likelihood of prior experience with these services, customers are also able to see the practical and functional benefits they provide. Past experience can influence customer attitude toward TESs, and this influence is mediated through customer readiness (i.e., role clarity, ability, and motivations) (J. S. Kim, Christodoulidou, \& Choo, 2013). Therefore, customers high on Optimism consider Established TESs to be more important because of the ability of these TESs to improve the flexibility, convenience, and productivity that Optimism measures. However, the paths from Optimism to Network Access and New TESs are not significant, a result that may be explained by a lack of benefits experienced by customers in relation to these new TESs.

The peripheral nature of many TESs implies an inability of these TESs to significantly enhance the core functionality of the booking and flight experience. In addition, customers do not necessarily perceive functional benefits from newly adopted TESs because of the perceived risks they associate with these services (Featherman \& Pavlou, 2003), resulting in an underappreciation of the benefits the services may offer.

In support of Hypotheses 2 and 3, Innovativeness is positively associated with Network Access and New, but negatively associated with Established TESs. This result occurs because Network Access and New TESs are recently introduced and appeal to innovative customers' intrinsic needs to be technological pioneers. To be considered an innovation, something needs to be new to the customers, the business, and the industry (Garcia \& Calantone, 2002). As Established TESs do not meet these criteria, they cannot satisfy innovators' need to be early 
adopters of radical innovations, resulting in the negative association between Innovativeness and Established TESs. The two inhibiting dimensions of Discomfort and Insecurity are not associated with perceived importance of all three groups of TESs. Therefore, Hypotheses 4 and 5 are not supported, a result that may be attributable to the service-oriented nature of airline TESs, which are designed to minimize the discomfort and insecurity a customer may experience.

Regarding Hypothesis 6, regression analysis for full-service airlines versus LCCs shows that the association between TR dimensions and perceived importance of TESs is more evident in the LCC group. As LCCs are more technologically advanced with a lower level of human touch in service delivery, travelers on these airlines have become accustomed to TESs, and thus are more likely to rate TESs as important. Multi-group analysis of the moderation effect of airline type (full-service vs. LCC) suggests that the effect marginally exists in relation to Optimism's effect on Network Access-related TESs, with the effect being significant only in the LCC sub-group. A possible explanation is that airline customers consider in-flight entertainment a core functional attribute of flight experience, but people traveling with LCCs do not enjoy the free in-flight entertainment options provided by full-service airlines. As the Internet has become a main channel for leisure and entertainment in life, LCC customers looking for more options and flexibility naturally extend the expectation of its availability to their flight experience as an alternative to fee-paid in-flight entertainment. In this sense, in terms of providing entertainment and convenience, Network Access is more functional and essential to LCC customers than to full-service airlines’ customers.

\section{Theoretical Implications}

This investigation has a number of theoretical implications related to research on technology-enabled services and TR. First, this study extends research on technology-based 
service classification, which has often included TESs from multiple industries and led to classifications based on criteria such as customization, standardization, and separability (e.g., Cunningham, Young, \& Gerlach, 2008; Meuter et al., 2000). However, these classifications may not apply to TESs available within a particular industry, because TESs within the same service category may exhibit similar degrees of customization, standardization, and separability.

Previous classification studies on self-service technologies are mainly conceptual and normative in nature, and they were undertaken primarily from a service provider's standpoint (Cunningham et al., 2008). In contrast, this study is based on empirical evidence and provides a simple customer-based typology for airline TESs that links to the degree of maturity of services and benefits they provide. This finding also differs from a prior finding that hotel employees categorized TESs on the basis of areas of functionality (Ham, Kim, and Jeong (2005), implying that service providers and customers approach TESs differently, with the former focusing on operational productivity and the latter focusing on experiences. TES-related research therefore needs to differentiate the customer perspective from the business perspective.

Second, this study deconstructs TR into its individual dimensions and includes a range of airline TESs. With this deconstruction, the study is better able to capture the dynamics and complexity of TR's influence, extending the knowledge regarding TR's role in shaping customer perception of TESs. For instance, previous research suggests that overall TR may not sufficiently explain the adoption of self-service options and that Innovativeness is an ineffective predictor of customers' attitudes toward these services (Liljander et al., 2006). This study shows that TR dimensions are linked to different categories of TESs, and that Innovativeness is positively associated with new TESs but negatively associated with established TESs. These findings and customers' differentiation between established and new TESs highlight the relevance of the 
technology lifecycle to the understanding of TES-related phenomena and suggest a need to differentiate between TESs at different stages of the lifecycle in future research related to TR and TESs.

Third, the result that Discomfort and Insecurity had no association with the perceived importance of TESs raises the issue of the relevance of these two dimensions in service delivery contexts. Researchers have also cited the instability issue of the negative dimensions (Gelderman et al., 2011; Liljander et al., 2006). Research is needed to further understand the role of these dimensions in affecting customer attitudes and behavior with respect to TESs.

\section{Managerial Implications}

This study offers a number of practical implications for airlines that want to effectively deploy TES-based strategies. First, the TES categories identified in this investigation differ from results produced by studies taking a service provider's perspective, implying a potential risk of mis-matching between customer need and TES offering. Many airlines see TESs as cost-saving tools, but to be successful the deployment of TESs must be coupled with other goals, such as better user experience, improved satisfaction, or greater understanding of customer needs. Airlines must understand the TES experience from both the business and customer perspective to ensure that technologies fit seamlessly into the way customers manage their flight experience.

Second, the findings help airlines work out roughly where each TES is situated on the technology lifecycle. To inform their strategies regarding TES provision and marketing, airlines should monitor how each TES moves through its lifecycle. For instance, products at different stages of the lifecycle are associated with different objectives and tactics within each element of the marketing mix (Dann \& Dann, 2007). As a TES moves from being newly implemented to being more mature, both its customer base and its competitive environment change. For example, 
previous studies have found that demographic variables do not consistently influence TES use (Meuter et al., 2003), and social demographics-based segmentation for TESs may not be effective. As this study shows, travelers high on different dimensions tend to distinguish new technologies from established technologies. A psychographic profiling of customers based on TR levels may provide a useful alternative for airlines.

Third, airlines should look not only at customers’ overall TR levels, but also at their relative standing in terms of the dimensions of TR. Airlines can differentiate between customers on the basis of their Optimism and Innovativeness about TESs and tailor promotional materials featuring different TESs. The abbreviated TR scale is a useful segmentation tool that a number of studies have used successfully to differentiate innovative customers from other customers on the basis of their scores on the four TR dimensions (e.g., Tsikriktsis, 2004; Victorino, Karniouchina, \& Verma, 2009). While implementing TR-based segmentation might be practically challenging, the findings of this study suggest that when advertising new and peripheral TESs, airlines should emphasize compatibility between TESs and customers’ motivations, personal goals, and lifestyle to appeal to innovative customers. In contrast, the promotion of established TESs needs to clearly demonstrate instrumental benefits, such as saving time and providing convenience, as these benefits are attractive to optimistic customers. In the actual delivery of TESs, airlines should also provide customers with clear instructions on how to use TESs.

Fourth, airlines can identify customers high on Innovativeness, who are likely to have expertise and control in using technologies, and treat them as operant resources rather than as a mere customer group. Research suggests that these customers are willing and able to participate in new service development, offering novel and original ideas as inputs into the product development process (Foxall, Goldsmith, \& Brown, 1998; Matthing et al., 2006). Some hotels 
have tried out new in-room technologies with guests who have skills and competency (Shaw et al., 2011), and airlines can adopt a similar strategy to explore innovative customers' experiences with new TES products in terms of aspects such as ease of use, convenience, reliability, and privacy, which affect customer adoption and evaluation of technologies (e.g., Dabholkar, 1996; Zhu et al., 2002).

Fifth, in promoting TESs, airlines have relied on travelers' intrinsic rather than extrinsic motivation under the assumption that travelers are able to see the benefits of these services through successful personal experience (Liljander et al., 2006). Consistent with prior research suggesting that extrinsic motivations are the most significant factors influencing TES use in a hotel setting (J. S. Kim et al., 2012), the lack of association between Optimism and new TESs revealed in this study may imply that many customers are not intrinsically motivated enough to adopt a new TES. As airlines cannot improve a customer's readiness for TESs overnight, extrinsic motivation is necessary if the intrinsic motivation is insufficient to motivate TES use (Dabholkar, 1996). Therefore, to promote customer use of new TESs, airlines must seek ways to more clearly demonstrate their practical benefits or promote TESs in combination with other benefits, such as award of airline miles (Liljander et al., 2006).

Sixth, this study demonstrates a difference between low-cost and full service airlines in terms of the way in which TR affects customers' perceived importance of TESs. In reality, lowcost airline customers may switch to a full-service airline (and vice versa) when circumstance requires (e.g., absence of service on a particular route or temporary financial constraint). Unavoidably, customers carry perceptions established from past experiences to the new service provider, creating complications for airlines. To maximize benefits of TES strategies, airlines 
should collect information from customers regarding their preferred airline type and past experience with TESs.

Finally, as established TESs cannot sufficiently satisfy innovators' need to be at the forefront of technology trends, airlines should continuously introduce new TESs or re-vitalize

existing TESs. For instance, US Airways has replaced its interactive voice response system with a system that personalizes messages by greeting callers with their names, proactively delivers information without callers asking for it, and anticipates the reasons for calling. While this system is expected to reduce call time and result in higher efficiency, it is also an effort of the airline to differentiate itself from other airlines through a better call experience (Nuance Communications, 2011), enhancing both utilitarian and hedonic benefits. Another focus of airlines with TESs in the established category should be managing service quality to achieve customer satisfaction.

While we acknowledge that implementing the above recommendations requires financial and human resources and may not be possible under all circumstances, the recommendations are nevertheless exciting possibilities that airlines could consider in TES deployment.

\section{Conclusions, Limitations, and Research Directions}

In conclusion, this study investigated the role of TR in influencing what TESs customers value in a purchase decision concerning airline services. The results established that two dimensions of TR—Optimism and Innovativeness—-were significant influencers of perceived importance of TESs. Travelers who reported higher levels of Optimism rated Established TESs as particularly important, whereas those high on Innovativeness rated Network Access and New TESs as more important. The association between TR dimensions and perceived importance of TESs is more evident in the low-cost carrier sub-group, suggesting a moderating role of type of 
airlines in the TESs and TR relationship. Theoretically, this study addresses an under-researched topic: TR's influence on customers' attitudes and experiences in relation to TESs. Practically, it provides managerial insights to airlines in relation to the deployment of TES-related strategies.

Limitations of this study arise from the research sample and survey instrument. The study drew the sample from a marketing list company's research panel using a quota sampling method and included respondents from a single country—Australia—which restricts the generalizability of the results. Additionally, to reduce the impact of respondent fatigue and improve data quality, the study used the abbreviated TR scale and included only TESs relevant to the Australian context. The interpretation of results is also based on the Australian context. As countries differ in their stages of technological development and adoption, a TES considered mature in Australia may not have been widely implemented in another country. Cross-country investigations of TES and TR-related phenomena would be of interest, such as a comparison of developed and emerging markets in relation to TR influence. Although the abbreviated TR scale has been previously validated, whether the results could be replicated using the full TR scale is not clear, and may be a topic that warrants future research effort.

Although Discomfort and Insecurity did not affect perceived importance of TESs, their influences should not be automatically dismissed, and further investigation is required to verify the finding of this study. Future research can also examine TESs from the airlines' standpoint to provide further insights into direct TES-related strategies, particularly as TES implementation requires both financial and human resources. A TR-based segmentation study for airlines is also recommended to help airlines strike a balance between satisfying innovators and less innovative customers. 


\section{References}

Agarwal, R., \& Prasad, J. (1998). A conceptual and operational definition of personal innovativeness in the domain of information technology. Information systems research, 9(2), 204-215.

Anderson, J. C., \& Gerbing, D. W. (1988). Structural equation modeling in practice: A review and recommended two-step approach. Psychological Bulletin, 103(3), 411-423.

Armstrong, J. S., \& Overton, T. S. (1977). Estimating nonresponse bias in mail surveys. Journal of Marketing Research, 14(3), 396-402.

Bagozzi, R. P., \& Heatherton, T. F. (1994). A general approach to representing multifaceted personality constructs: Application to state self-esteem. Structural Equation Modeling: A Multidisciplinary Journal, 1(1), 35-67.

Bagozzi, R. P., \& Yi, Y. (1988). On the evaluation of structural equation models. Journal of the Academy of Marketing Science, 16(1), 74-94.

Beatson, A., Coote, L. V., \& Rudd, J. M. (2006). Determining consumer satisfaction and commitment through self-service technology and personal service usage. Journal of Marketing Management, 22(7-8), 853-882.

Cattell, R. B. (1966). The scree plot for the number of factors. Multivariate Bahavioural Research, 1(2), 245-276.

Cheng, S., \& Cho, V. (2011). An integrated model of employees' behavioral intention toward innovative information and communication technologies in travel agencies. Journal of Hospitality \& Tourism Research, 35(4), 488-510.

Cunningham, L. F., Young, C. E., \& Gerlach, J. H. (2008). Consumer views of self-service technologies. The Service Industries Journal, 28(6), 719-732. 
Dabholkar, P. A. (1996). Consumer evaluations of new technology-based self-service options: an investigation of alternative models of service quality. International Journal of research in Marketing, 13(1), 29-51.

Dann, S., \& Dann, S. (2007). Competitive marketing strategy. Frenchs Forest, NSW, Australia: Pearson Education Australia.

Featherman, M. S., \& Pavlou, P. A. (2003). Predicting e-services adoption: A perceived risk facets perspective. International Journal of Human-Computer Studies, 59(4), 451-474.

Fornell, C., \& Larcker, D. F. (1981). Evaluating structural equation models with unobservable variables and measurement error. Journal of Marketing Research, 18(1), 39-50.

Foxall, G., Goldsmith, R., \& Brown, S. (1998). Consumer psychology for marketing (2 Ed.). London: International Thomson Business Press.

Garcia, R., \& Calantone, R. (2002). A critical look at technological innovation typology and innovativeness terminology: A literature review. Journal of product innovation management, 19(2), 110-132.

Gelderman, C. J., Ghijsen, P. W. T., \& van Diemen, R. (2011). Choosing self-service technologies or interpersonal services-The impact of situational factors and technologyrelated attitudes. Journal of Retailing and Consumer Services, 18(5), 414-421.

Hair, J. F., Black, W. C., Babin, B. J., Anderson, R. E., \& Tatham, R. L. (2006). Multivariate data analysis (6 ed.). Upper Saddle River, NJ: Pearson Prentice Hall.

Ham, S., Kim, W. G., \& Jeong, S. (2005). Effect of information technology on performance in upscale hotels. International Journal of Hospitality Management, 24(2), 281-294.

Hoon, Y. S. (2012). Etihad, Cathay see technology as key to owning the customer. Retrieved December 2, 2012, from http://www.webintravel.com/news/etihad-cathay-seetechnology-as-key-to-owning-the-customer_3474 
International Air Transport Association. (2011). Vision 2050. Singapore: International Air Transport Association.

Karande, K., Merchant, A., \& Sivakumar, K. (2011). Erratum to: Relationships among time orientation, consumer innovativeness, and innovative behavior: the moderating role of product characteristics. AMS Review, 1(2), 99-116.

Kim, D. Y., Park, J., \& Morrison, A. M. (2008). A model of traveller acceptance of mobile technology. International Journal of Tourism Research, 10(5), 393-407.

Kim, J. S., Christodoulidou, N., \& Brewer, P. (2012). Impact of individual differences and consumers’ readiness on likelihood of using self-service technologies at hospitality settings. Journal of Hospitality \& Tourism Research, 36(1), 85-114.

Kim, J. S., Christodoulidou, N., \& Choo, Y. (2013). Factors influencing customer acceptance of kiosks at quick service restaurants. Journal of Hospitality and Tourism Technology, 4(1), 40-63.

Kim, M., \& Qu, H. (2014). Travelers' behavioral intention toward hotel self-service kiosks usage. International Journal of Contemporary Hospitality Management, 26(2), 225-245.

Kokkinou, A., \& Cranage, D. A. (2012). Using self-service technology to reduce customer waiting times. International Journal of Hospitality Management, 33, 435-445.

Lee, W. I., Chiu, Y. T. H., Chiang, M. H., \& Chiu, C. C. (2009). Technology readiness in the quality-value-loyalty chain. International Journal of Electronic Business Management, $7(2), 112-126$.

Li, X., Hess, T. J., \& Valacich, J. S. (2008). Why do we trust new technology? A study of initial trust formation with organizational information systems. The Journal of Strategic Information Systems, 17(1), 39-71.

Liljander, V., Gillberg, F., Gummerus, J., \& van Riel, A. (2006). Technology readiness and the evaluation and adoption of self-service technologies. Journal of Retailing and Consumer Services, 13(3), 177-191. 
Lin, C. H. (2009). The effects of utilitarian shopping and technology belief on perceived eservice value. Paper presented at the Portland International Center for Management of Engineering and Technology (PICMET) 2009, Portland, OR.

Lin, C. H., Shih, H. Y., \& Sher, P. J. (2007). Integrating technology readiness into technology acceptance: The TRAM model. Psychology \& Marketing, 24(7), 641-657.

Lin, J. S. C., \& Hsieh, P. L. (2007). The influence of technology readiness on satisfaction and behavioral intentions toward self-service technologies. Computers in Human Behavior, 23(3), 1597-1615.

Lu, J. L., Choi, J. K., \& Tseng, W. C. (2011). Determinants of passengers' choice of airline check-in services: A case study of American, Australian, Korean, and Taiwanese passengers. Journal of Air Transport Management, 17(4), 249-252.

Massey, A. P., Khatri, V., \& Montoya-Weiss, M. M. (2007). Usability of online services: The role of technology readiness and context. Decision Sciences, 38(2), 277-308.

Matthing, J., Kristensson, P., Gustafsson, A., \& Parasuraman, A. (2006). Developing successful technology-based services: the issue of identifying and involving innovative users. Journal of Services Marketing, 20(5), 288-297.

Meuter, M. L., Ostrom, A. L., Bitner, M. J., \& Roundtree, R. I. (2003). The influence of technology anxiety on consumer use and experiences with self-service technologies. Journal of Business Research, 56(11), 899-906.

Meuter, M. L., Ostrom, A. L., Roundtree, R. I., \& Bitner, M. J. (2000). Self-service technologies: understanding customer satisfaction with technology-based service encounters. Journal of Marketing, 64(3), 50-64.

Netemeyer, R. G., Bearden, W. O., \& Sharma, S. (2003). Scaling procedures: Issues and applications. Thousand Oaks, CA: Sage Publications.

Nuance Communications. (2011). US airways reaches new heights in customer service with a fast, personalised self-service IVR system powered by Nuance. Retrieved December 18, 
2012, from http://www.nuance.com/ucmprod/groups/enterprise/@webenus/documents/collateral/nc_019760.pdf

O’Connell, J. F., \& Williams, G. (2005). Passengers' perceptions of low cost airlines and full service carriers: A case study involving Ryanair, Aer Lingus, Air Asia and Malaysia Airlines. Journal of Air Transport Management, 11(4), 259-272.

Oh, H., Jeong, M., Lee, S. A., \& Warnick, R. (2013). Attitudinal and situational determinants of self-service technology use. Journal of Hospitality \& Tourism Research, Forthcoming.

Parasuraman, A. (2000). Technology Readiness Index (TRI) a multiple-item scale to measure readiness to embrace new technologies. Journal of Service Research, 2(4), 307-320.

Pentecost, R., \& Andrews, L. (2013). The importance of importance: Its impact on decisionmaking in mall retail categories during an economic downturn. Journal of Retailing and Consumer Services, 20(5), 463-470.

Rogers, E. M. (1995). Diffusion of innovations (4 ed.). New York: Free Press.

Shaw, G., Bailey, A., \& Williams, A. (2011). Aspects of service-dominant logic and its implications for tourism management: Examples from the hotel industry. Tourism Management, 32(2), 207-214.

Tabachnick, B. G., \& Fidell, L. S. (2001). Using multivariate statistics. Upper Sandle River, NJ: Pearson Education.

Tam, J. L. M. (2011). The moderating effects of purchase importance in customer satisfaction process: An empirical investigation. Journal of Consumer Behaviour, 10(4), 205-215.

Theotokis, A., Vlachos, P. A., \& Pramatari, K. (2008). The moderating role of customertechnology contact on attitude towards technology-based services. European Journal of Information Systems, 17(4), 343-351.

Torres, A. M., Barry, C., \& Hogan, M. (2009). Opaque web practices among low-cost carriers. Journal of Air Transport Management, 15(6), 299-307. 
Tourism Research Australia. (2012a). Tourism Investment Monitor, 2012. Canberra, ACT: Tourism Research Australia, Department of Resources, Energy and Tourism.

Tourism Research Australia. (2012b). Tourism’s Contribution to the Australian Economy, 199798 to 2010-11. Canberra, ACT: Tourism Research Australia, Department of Resources, Energy and Tourism.

Tsikriktsis, N. (2004). A technology readiness-based taxonomy of customers a replication and extension. Journal of Service Research, 7(1), 42-52.

van der Heijden, H. (2004). User acceptance of hedonic information systems. MIS quarterly, 28(4), 695-704.

Venkatesh, V., \& Brown, S. A. (2001). A longitudinal investigation of personal computers in homes: adoption determinants and emerging challenges. MIS quarterly, 25(1), 71-102.

Victorino, L., Karniouchina, E., \& Verma, R. (2009). Exploring the use of the abbreviated Technology Readiness Index for hotel customer segmentation. Cornell Hospitality Quarterly, 50(3), 342-359.

Walczuch, R., Lemmink, J., \& Streukens, S. (2007). The effect of service employees’ technology readiness on technology acceptance. Information \& Management, 44(2), 206-215.

Weiten, W. (2004). Psychology: Themes and variations (6 ed.). Belmont, CA: Thomson.

Westjohn, S. A., Arnold, M. J., Magnusson, P., Zdravkovic, S., \& Zhou, J. X. (2009).

Technology readiness and usage: A global-identity perspective. Journal of the Academy of Marketing Science, 37(3), 250-265.

Yi, Y., Tung, L. L., \& Wu, Z. (2003). Incorporating technology readiness (TR) into TAM: Are individual trait important to understand technology acceptance? Paper presented at the Diffusion Interest Group in Information Technology (DIGIT) Workshop, Seattle, WA.

Zhu, F. X., Wymer, W., \& Chen, I. (2002). IT-based services and service quality in consumer banking. International Journal of Service Industry Management, 13(1), 69-90. 
Table 1

Sample Profile

\begin{tabular}{lll}
\hline Variables & Valid N & $\%$ \\
\hline Gender $(N=485)$ & 247 & \\
$\quad$ Male & 238 & 40.9 \\
Female & & \\
Age $(N=480)$ & 84.1 \\
Under 29 years & 119 & 17.5 \\
30-39 years & 87 & 24.8 \\
40-49 years & 90 & 18.1 \\
50-59 years & 100 & 18.8 \\
60 years or above & & 20.8 \\
Highest qualification $(N=485)$ & 39 & 8.0 \\
Completed year 10 or less & 81 & 16.7 \\
Completed year 11 or 12 & 89 & 18.4 \\
College certificate or diploma & 47 & 9.7 \\
Trade qualification & 128 & 26.4 \\
Undergraduate degree & 97 & 20.0 \\
Postgraduate degree & 4 & .8 \\
Other & & \\
Gross household income $(N=476)$ & 84 & 17.6 \\
\$40,000 or less & 91 & 19.1 \\
\$40,001-60,000 & 75 & 15.8 \\
\$60,001-80,000 & 82 & 17.2 \\
\$80,001-100,000 & 97 & 20.4 \\
\$100,001-150,000 & 9.9 \\
Greater than \$150,000 & 47 & \\
Relationship status ( $N=485$ ) & & 20.6 \\
Single & 100 & 71.5 \\
Married/de facto relationship & 347 & .4 \\
Separated/Divorced/Widowed & 36 & \\
Other & 2 & \\
\hline
\end{tabular}




\section{Table 2}

\section{Results of Exploratory Factor Analysis}

\begin{tabular}{|c|c|c|c|c|}
\hline Item Description & Network & Established & New & $\alpha$ \\
\hline Network & & & & .94 \\
\hline In-flight wireless Internet access & .91 & & & \\
\hline In-flight high-speed Internet access & .86 & & & \\
\hline In-seat Internet cable access & .85 & & & \\
\hline In-flight WiFi Intranet & .81 & & & \\
\hline Wireless Internet access in the airport & .58 & & & \\
\hline Established & & & & .87 \\
\hline $\begin{array}{l}\text { Web check-in/ Print at home boarding } \\
\text { pass }\end{array}$ & & .83 & & \\
\hline On-line booking capability & & .78 & & \\
\hline Email boarding pass & & .70 & & \\
\hline Individual airline website & & .66 & & \\
\hline Express check-in/ Self-check-in kiosks & & .64 & & \\
\hline Free in-flight entertainment & & .52 & & \\
\hline Presence on major booking websites & & .51 & & \\
\hline Central reservation number & & .49 & & \\
\hline Email contact & & .47 & & \\
\hline New and Peripheral & & & & .88 \\
\hline SMS boarding pass & & & .67 & \\
\hline Presence on social media & & & .66 & \\
\hline Flight booking facility on board & & & .64 & \\
\hline Additional fee-paying entertainment & & & .59 & \\
\hline Mobile Smartphone check-in & & & .58 & \\
\hline In-flight long distance telephone calls & & & .56 & \\
\hline $\begin{array}{l}\text { Mobile WAP-based reservation } \\
\text { systems }\end{array}$ & & & .56 & \\
\hline
\end{tabular}




\section{Table 3}

Results for Confirmatory Factor Analysis

\begin{tabular}{|c|c|c|c|}
\hline Factor and item description & SL & TV & CR \\
\hline Optimism $\quad($ Mean $=5.00, \mathrm{SD}=1.04)$ & & & .71 \\
\hline You like computer programs that allow you to tailor things to fit your own needs & .70 & N/A & \\
\hline You find new technologies to be mentally stimulating & .79 & 13.25 & \\
\hline Innovativeness $\quad($ Mean $=4.35, \mathrm{SD}=1.30)$ & & & .80 \\
\hline Other people come to you for advice on new technologies & .85 & N/A & \\
\hline $\begin{array}{l}\text { In general, you are among the first in your circle of friends to acquire new technology when } \\
\text { it appears }\end{array}$ & .76 & 16.89 & \\
\hline You can usually figure out new high-tech products and services without help from others & .67 & 14.80 & \\
\hline Insecurity $\quad($ Mean $=3.93, \mathrm{SD}=1.23)$ & & & .74 \\
\hline You do not consider it safe to do any kind of financial business online & .72 & N/A & \\
\hline You worry that information you send over the Internet will be seen by other people & .70 & 11.63 & \\
\hline $\begin{array}{l}\text { If you provide information to a machine or over the Internet, you can never be sure it really } \\
\text { gets to the right place }\end{array}$ & .67 & 11.38 & \\
\hline $\begin{array}{l}\text { Discomfort } \quad(\text { Mean }=3.96, \mathrm{SD}=1.17) \\
\text { It is embarrassing when you have trouble with a high-tech gadget while people are watching }\end{array}$ & .60 & N/A & .51 \\
\hline $\begin{array}{l}\text { When you get technical support from a provider of a high-tech product or service, you } \\
\text { sometimes feel as if you are being taken advantage of by someone who knows more than } \\
\text { you do }\end{array}$ & .57 & 7.14 & \\
\hline $\begin{array}{l}\text { Established } \quad(\text { Mean }=5.70, \mathrm{SD}=0.88) \\
\text { Web check-in/ Print at home boarding pass }\end{array}$ & .75 & N/A & .87 \\
\hline On-line booking capability & .68 & 14.62 & \\
\hline Email boarding pass & .76 & 16.43 & \\
\hline Express check-in / Self-check-in kiosks & .70 & 15.16 & \\
\hline Individual airline website & .59 & 12.48 & \\
\hline Central reservation number & .58 & 12.29 & \\
\hline Presence on major booking websites & .62 & 13.30 & \\
\hline Free in-flight entertainment & .50 & 10.50 & \\
\hline Email contact & .64 & 13.62 & \\
\hline $\begin{array}{l}\text { Network Access } \quad(\text { Mean }=5.07, \mathrm{SD}=1.35) \\
\text { In-flight wireless Internet access }\end{array}$ & .93 & N/A & .94 \\
\hline In-flight high-speed Internet access & .90 & 33.56 & \\
\hline In-seat Internet cable access & .89 & 32.25 & \\
\hline In-flight WiFi Intranet & .89 & 33.19 & \\
\hline Wireless Internet access in the airport & .69 & 19.24 & \\
\hline New $\quad($ Mean $=4.35, \mathrm{SD}=1.30)$ & & & .89 \\
\hline Presence on social media & .66 & N/A & \\
\hline Flight booking facility on board & .75 & 14.29 & \\
\hline In-flight long-distance telephone calls & .72 & 14.00 & \\
\hline Additional fee-paying entertainment & .52 & 10.42 & \\
\hline SMS boarding pass & .78 & 14.82 & \\
\hline
\end{tabular}


Mobile WAP-based reservation systems

$.79 \quad 14.98$

Mobile Smartphone check-in

$.84 \quad 15.70$

Notes: $\chi^{2}=1218.73(p<.01$, d.f. $=416) ; \chi^{2} /$ d.f. $=2.95$; CFI = .90; NFI = .87; TLI = .88; RMSEA = .063; SL = standardized loadings; $\mathrm{TV}=t$ value; $\mathrm{CR}=$ composite reliability; $\mathrm{AVE}=$ average variance extracted 
Table 4

Results of Structural Model

\begin{tabular}{|c|c|c|c|c|c|c|}
\hline Path & & & Beta wt. & S.E. & C.R. & Hypothesis \\
\hline ESD & $<---$ & OPT & $.79 * * *$ & .165 & 5.731 & \multirow{3}{*}{ H1 } \\
\hline NET & <--- & OPT & $.22 * *$ & .203 & 2.102 & \\
\hline NEW & <--- & OPT & .15 & .161 & 1.473 & \\
\hline ESD & <--- & INN & $-.27 * *$ & .089 & -2.219 & $\mathrm{H} 2$ \\
\hline NET & $<---$ & INN & $.28 * * *$ & .118 & 2.733 & \multirow{2}{*}{ H3 } \\
\hline NEW & $<---$ & INN & $.45^{* * *}$ & .098 & 4.451 & \\
\hline ESD & <--- & DIS & -.10 & .147 & -.737 & \multirow{3}{*}{$\mathrm{H} 4$} \\
\hline NET & <--- & DIS & -.12 & .218 & -.958 & \\
\hline NEW & <--- & DIS & .07 & .170 & .597 & \\
\hline ESD & <--- & INS & .08 & .102 & .642 & \multirow{3}{*}{ H5 } \\
\hline NET & <--- & INS & $.22 *$ & .151 & 1.890 & \\
\hline NEW & $<---$ & INS & .13 & .118 & 1.192 & \\
\hline
\end{tabular}




\section{Table 5}

\section{Revised Structural Model Results}

\begin{tabular}{ccclll}
\hline Path & & & Beta wt. & S.E. & C.R. \\
\hline ESD & $\leftarrow$ & OPT & $.764^{* * *}$ & .147 & 6.220 \\
ESD & $\leftarrow$ & INN & $-.243^{* *}$ & .078 & -2.258 \\
NET & $\leftarrow$ & INN & $.326^{* * *}$ & .105 & 3.597 \\
NET & $\leftarrow$ & OPT & $.163^{*}$ & .180 & 1.736 \\
NEW & $\leftarrow$ & INN & $.464^{* * *}$ & .089 & 4.944 \\
NEW & $\leftarrow$ & OPT & .121 & .146 & 1.304 \\
\hline Notes: $* * * p$-value & $<.01 ; * * p$-value $<.05 * * p$-value $<.10$
\end{tabular}




\section{Table 6}

\section{Results of Multi-group Analysis for Full-service and Low-cost Airlines}

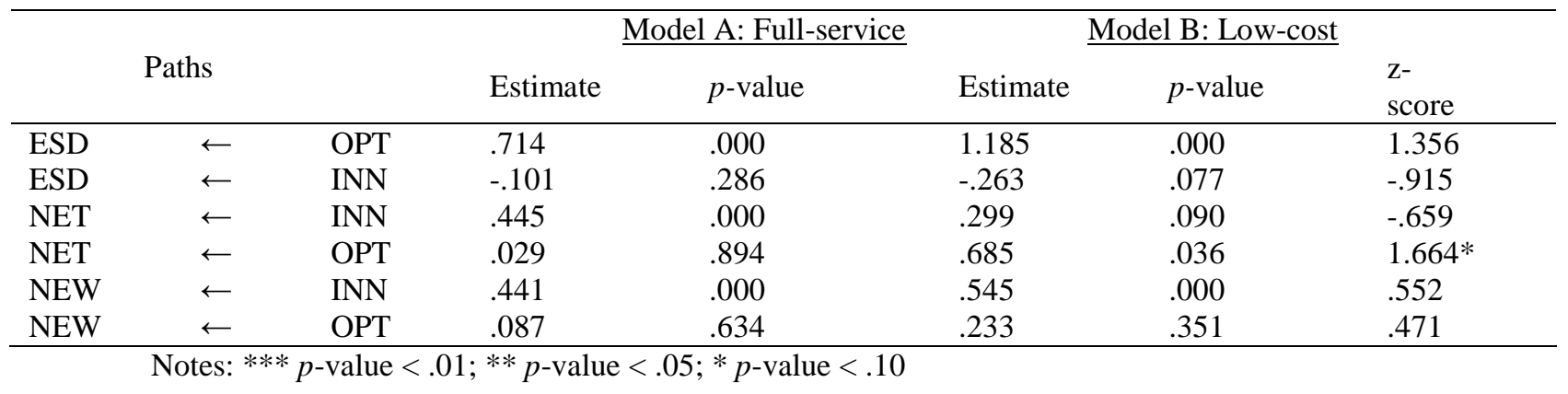


Figure 1

Revised Structural Model

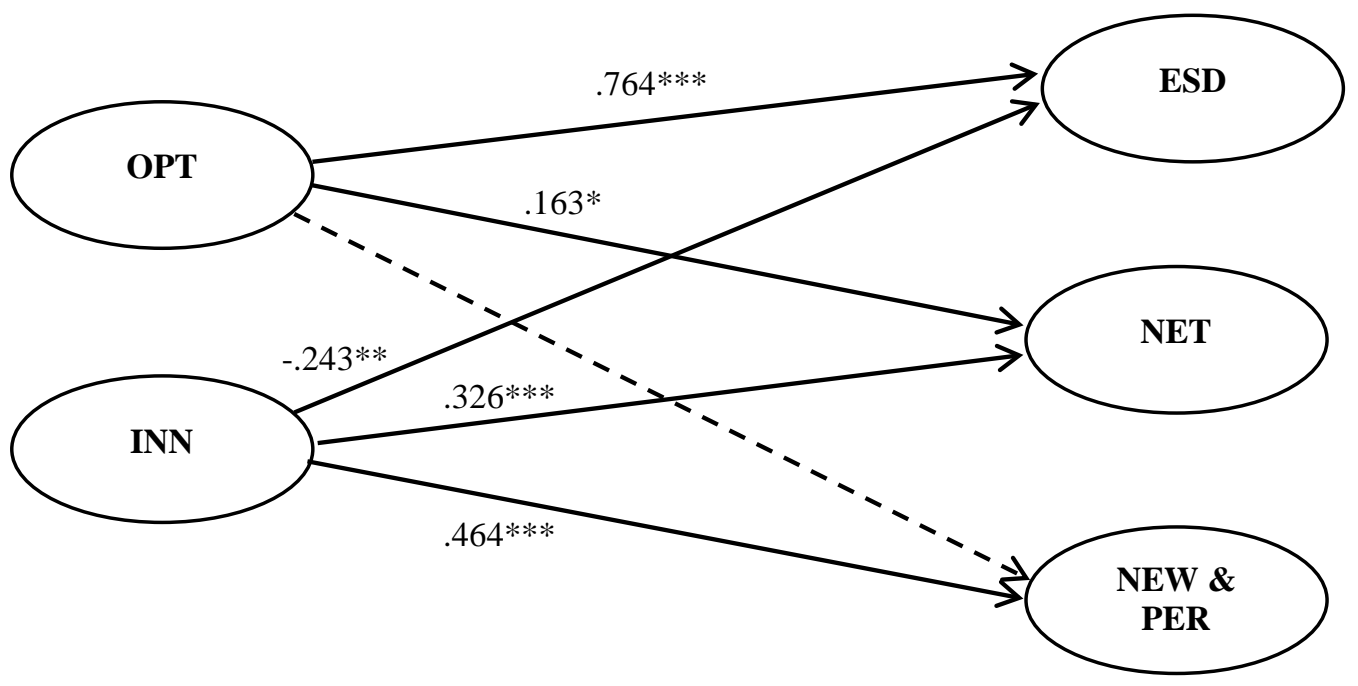

